ISSN 0975-3311

Ushus JBMgt, 9, 2 (2010) 73-80

ISSN 0975-3311 | https://doi.org/10.12725/ujbm.17.6

\title{
STRATEGIC INNOVATION IN THE FINANCIAL SERVICES INDUSTRY IN INDIA: TRENDS AND CHALLENGES
}

\author{
Ashraf Imam*
}

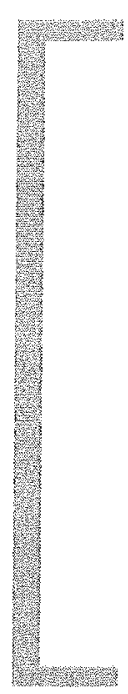

ABSTRACT

Strategic innovation is a hot topic in management today, but there is a wide gap between the aspirations of executives to innovate and their ability to execute. Many try, but few succeed! Why does strategic innovation pose so many challenges for incumbent firms? And how can established firms cope with these challenges? This paper addresses these questions as it explores what strategic innovation is and how it differs from the product and service innovation literature. It then describes the major challenges associated with strategic innovation and outlines how coped with these challenges. It is argued that strategic innovation is a crucial driver of growth, performance, and valuation. That is why an increasing number of financial institutions have put 'innovation' on the top of their corporate agenda. But research has revealed that there is a wide gap between the aspirations of executives to innovate and their ability to execute, especially when it comes to strategic innovation. Nevertheless, some financial institutions

\footnotetext{
* Dept. of Commerce, Aligarh Muslim University, Aligarh. Email : imamashrafl@rediffmail.com
} 
have changed the rules of the game in the financial services industry. This paper begins with an overview of innovation and why it is important. Innovation impacts every business sector today and financial services are no different. But is it easy to create the right environment to promote innovation? Research and development should be one of the top sources for generating innovation yet studies show that in the financial services it is relatively low. Our conclusion is that strategic innovation requires a strategic commitment and the adoption of particular management processes and systems to create, nurture, and develop new businesses. Managers should be aware of the threats and opportunities associated with strategic innovation before they ask the organization to engage in innovation.

Keywords: Strategic Innovation, Management, Challenges, Innovation, Financial services Industry.

\section{Introduction}

Ilndian financial-services industries see innovation as very important to the ability of their company to meet short- and long-term performance targets. Several survey findings suggest that innovation will be a major competitive battleground in the financial-services industry. Respondents, who represent public and private firms in financial services, consider product innovation to be very important and view business model innovation as growing in importance. However, a majority of the executives surveyed by the reputed company view that innovation as more challenging for financial services industry in India than for companies in other sectors. And in their survey respondents said that their company has significant room to improve performance on a number of common best practices for fostering innovation, such as using consumer insights to drive new ideas and dedicating organizational structures and funds to innovation. Strategic innovation is a hot topic in management today. It is argued that strategic innovation is a crucial driver of growth, performance, and valuation. That is why an increasing number of financial institutions have put 'innovation' on the top of their corporate agenda. But some research has revealed that there is a wide gap between the aspirations of executives to innovate and their ability to execute, especially when it comes to strategic innovation. In particular, established financial services industry in India finds it difficult to translate their innovation ambitions into successful projects and new businesses. 


\section{Strategic innovation}

The American Heritage Dictionary defines Innovation as "the act of The American Heritage Dictionary defines Innovation as "the act of introducing something new". The Department of Trade and Industry in the UK defines Innovation as "the successful exploitation of ideas".

Innovation comes from the Latin innovātus which means to renew. Innovation can therefore be seen as the process that renews something that exists and not, as is commonly assumed, the introduction of something new.

In the organizational context, innovation may be linked to changes in efficiency, productivity, quality, competitive positioning, market share, etc. can all be affected positively or negatively by innovative forces. All organizations can innovate, including for example hospitals, universities, and local governments. Some will flourish under its influence. Other will die.

So as innovation typically changes value, innovation may also have a negative or destructive effect as new developments clear away or change old organizational forms and practices. Organizations that do not compensate effectively for innovative forces (mainly from outside) may be destroyed by those that do. Hence managing an organization typically involves risk. A key challenge in management is maintaining a balance between the current processes and business model. Innovation has been studied in a variety of contexts, including in relation to technology, commerce, social systems, economic development, and policy construction.

Strategic innovation define as the ability of an organization to create customer value by effectively delivering the customer total satisfaction through the transformation of creative ideas and thereby growing the business. In the case of the Nano, the "Job-to-be-Done" was to provide safe transportation to individuals at low cost. Tata Motors then used the power of innovation to create a product that is priced at less than $50 \%$ of what is available today. Creating and delivering new innovations for many companies will depend on their ability to define the "Job-to-be-Done" for their customers.

Strategic innovation is more than investing in R\&D and then launching nextgeneration products or services. For strategic innovation to occur, activities and capabilities are leveraged in such a way as to offer customer value that breaks with established industry recipes. Strategic innovation is not so 
much about the creation of new-to-the-world products and services. Many managers confuse product innovation with strategic innovation. Strategic innovation has received a lot of attention in recent years for two major reasons. The first reason is that the performance benefits of strategic innovations are considered to be much higher than traditional product innovation. Many managers in the financial services industry will agree that product innovations only marginally contribute to a sustainable competitive advantage. Product innovations can be easily copied, in contrast to strategic innovation. Furthermore, strategic innovators enjoy the benefit of creating a new market space. Associated with this are the advantages of uniqueness: a first mover advantage, a temporary monopoly, switching costs, and subsequent customer Loyalty.

The second reason is that it poses serious threats for the incumbents Strategic innovation is a powerful force that drives established leaders to set the stage for their own destruction. As a result, managers of established firms try to better understand what strategic innovation involves in order developing appropriate strategic responses to these new competitors.

The areas of focus in innovation may vary in product-based, servicebased, or manufacturing concern. But the underlying variables and dimensions would remain constant in all the organizations. The Institutions who have delivered world class products and services and have remained globally competitive for various years and have sustained global competitiveness have always had a special focus on having a dedicated team on Research and Development with a very high degree of commitment. The practice of strategic innovation management shall ensure the global competitiveness, overall productivity and value maximization of the firm

\section{Trends \& Challenges of Strategic Innovation}

Obstacle's that currently facing in strategic innovation: Firstly, the management of financial services industry often lacks the motivation to strategically innovate. Innovation has become one of the buzz words in management today, and that is why many companies report it as one of their strategic priorities. The reality, however, is that few companies explicitly lead and manages innovation. The main reason is the innovation approach many companies pay attention to innovation but do nothing about it. Innovation is tackled on an ad hoc basis, and is not integrated in the company's management core processes. It is often encouraged, but almost 
never managed, tracked, and measured. We already outlined that strategic innovation, which is about breaking the rules of the game, is perceived to be crucial in today's competitive environment. However, the vast majority of innovation projects of a typical company can be grouped into the following categories: (1) copied or minor changes /extensions of the current product lines, (2) cost saving innovations on current projects, and (3) newto-the-company, but not new-to the-market innovations.

Second major challenges that for financial services industries encounter in strategic innovation are situated in the ideas generation phase. When asked what inhibits innovation in their organization, managers report they lack the right people to strategically innovate (lacking of right innovative ideas).

Need to move from innovation as the product of visionaries to innovation as the product of activists. Consequently, the problem of most companies is not that they lack the right people, what they lack is an appropriate corporate culture that stimulates openness for new ideas and a willingness to take risks and to experiment and to do engage your management team to come up with totally new ideas. Strategic innovation is not only a matter of corporate culture, but also of appropriate organizational structures. This is one of the most decisive factors to make strategic innovation work. Strategic innovations are set up in an environment that is encouraging to experimentation and exploration. In most cases, innovative companies have set up a separate unit within their organization. It is important that the new unit is stimulated to break free from the pack and to challenge conventional wisdom. In the early stages, strategic innovations occur in the side-line of the core business, but when successful new initiatives receive widespread attention within the corporation. At that moment, these initiatives become very at risk for withdrawal there are always more urgent strategic priorities to invest in. That is why you need the high-level support to protect the venture.

Innovation is not only about inventing and conceiving new ideas. The new ideas need to be commercialized and turned into financially attractive projects. Many strategic innovations are mismanaged in the innovation project development phase. Strategic innovations need to be managed in a totally different way than the mature business lines. Executives from financial services industry typically view a meticulous financial planning and review process as a crucial asset. Divergences from the plan are a bad thing. It 
means that the business is no longer under control. In contrast, strategic innovations call for a company to visualize what is unknown and uncertain. No business can be emerged as the safe, reliable \& the well-understood business. Strategic innovations can digress substantially from their original planned targets. Learning will be fostered if the attention is taken away from the pure figures. It is much more important to openly discuss setbacks and surprises with higher-level managers, and this transparency on the underlying assumptions is a necessary basis for learning.

The last challenge for project section of any financial services industry to successfully innovate is to move from the 'innovation project mode' to the 'development mode.' Having identified a hole in the market is not enough; you need to transform the innovation project into a mature business. But this is extremely challenging. The new unit should now embrace what it always has rejected: a more structured and formal approach towards the management of the business. Managers will also have to deal with political pressures as the innovation project has to begin abiding by the corporate rules. The unit will have to deal with rules about overhead and transfer prices, HR policies, IT policies, and other centralized systems. Covetousness, turf battles, and political tensions increasingly become part of the game. A crucial question in this phase is whether to integrate the new unit in the current business structures or to keep it as a separate business line. The answer is not straightforward. By keeping the new organization separate, you avoid the compromise costs that are associated with managing dual business models. On the other hand, you might give up exploiting the synergies between the two organizations. Managing dual business models is difficult, and poses significant challenges to corporate-level managers.

Thus the challenges of strategic innovation for financial Services industry in India:

- Motivation to innovate

- Generation of breakthrough ideas

- Innovation project management skills

- Business management skills

FFurthermore, it is very important to let the new business enterprise develop its own culture. In start-up businesses, the culture is characterized by high levels of entrepreneurship and open-up mindsets. Other elements of a 
pioneering culture are a high degree of flexibility and the free sharing of information inside and outside the organization. There is a lot of creativity, and an open discussion of new initiatives. Experimentation is supported, not punished. In reality, many sections lack that innovative spirit and exploration mindset. Financial services industry is considered to be one of the most risk-averse in the corporate world and innovation has never been put high on the agenda, since product innovations could be copied almost instantly. Nevertheless, there are some interesting examples of financial firms that have successfully launched strategic innovation projects.

\section{Conclusion}

The areas of focus in innovation may vary in product-based, servicebased, or manufacturing concern. But the underlying variables and dimensions would remain constant in all the organizations. The Institutions who have delivered world class products and services and have remained globally competitive for various years and have sustained global competitiveness have always had a special focus on having a dedicated team on Research and Development with a very high degree of commitment. The practice of strategic innovation management shall ensure the global competitiveness, overall productivity and value maximization of the firm. The well structured deliverables from a well structured team. The dedicated team for research and development carries on the research in different areas.

The importance of innovation management in value maximization of a firm is very important in the light of the rapid changes in the business dynamics internationally in digital economies. To summaries, strategic innovation is an important key to attain global competitiveness and value maximization.

Strategic innovation is a hot topic in the financial services industry and the managers of financial services industry do not only speculate how to play the existing diversion better, but are also looking for new diversions. Our experience tells us however that strategic innovation is often not taken seriously by the top management. There is a wide gap between the aspirations of executives to innovate and their ability to execute. In reality, financial firms lack the real motivation to innovate strategically. Top management is not committed, and they do not want to invest. They hope for a lucky shot by one of their lower-level managers, but forget to provide these managers with the right organizational environment. 
Strategic innovations must be developed and nurtured in a separate business. Equally important is that companies ensured that the unit is supported and protected by a powerful high-level manager who understands the sensitivities in the organization. The managers of the new businesses have to ensure that the innovation projects are managed appropriately. Focus should not be on managing budgets; what matters is learning. Learning makes it possible to refine the new business concept, and to grow it into a new business. Probably this is one of the biggest challenges for strategic innovators. All this indicates that strategic innovation is a challenging job.Many financial industry tries to innovate new ideas and implement it but few of them succeed. We all are aware of the threats and opportunities associated with strategic innovation. Simply jumping into a water pool does not assurance you reach the other side.

\section{References}

Anderson \& Markides, August 2006, "Strategic Innovation at the Base of the Economic Pyramid," (Available at www.ssrn.com).

Barsh, J., M. M. Capozzi, and J. Davidson, 2008, "Leadership and innovation," McKinsey Quarterly, 1, 37-47.

Debruyne, M. and M. Schoovaerts, 2006, "Innovation outside the lab: strategic innovation as the alternative, "Research Report Flanders District of Creativity, October, 1-40.

Govindarajan, V., and C. Trimble, 2004, "Strategic innovation and the science of learning," MIT Sloan Management Review, Winter, 67-75.

Markides, C. C., 2000, All the right moves: a guide to crafting breakthrough strategy, Harvard Business School Press, Boston, MA.

Markides, C. C., 2006, "Disruptive innovation: In need of better theory," Journal of Product Innovation Management, 23, 19-25.

Moore, G. A., 1991, Crossing the chasm: marketing and selling high-tech products to mainstream customers, HarperCollings, New York, NY.

O'Reilly III, C. A., and M. L. Tushman, 2004, "The ambidextrous organization," Harvard Business Review, April, 74-81.

Styles, C. and J. Goddard, 2004, "Spinning the wheel of strategic innovation," Business Strategy Review, 15:2, 63-72. 